\title{
INFLUÊNCIA DA COBERTURA MORTA NA RETENÇÃO DO IMAZAQUIN EM PLANTIO DIRETO DE SOJA ${ }^{1}$
}

\author{
BENEDITO N. RODRIGUES ${ }^{2}$, JOÃO DE LIMA ${ }^{3}$, INÊS F. U. YADA ${ }^{4}$, ADOLFO V. ULBRICH ${ }^{5}$ e DONIZETI A. FORNAROLLI ${ }^{5}$
}

\section{RESUMO}

Os resíduos das plantas constituem-se na parte mais importante do sistema de plantio direto. Apesar da cobertura reduzir a população de ervas, ela pode interceptar os herbicidas quando aplicados sobre a palha. Experimentos a campo, bioensaios e análises cromatográficas foram realizados, utilizando-se o imazaquin nas doses de zero, 75,150 e $300 \mathrm{~g} / \mathrm{ha}$, aplicado sobre 7000 e $14000 \mathrm{~kg} / \mathrm{ha}$ de resíduos de aveia-preta (Avena strigosa Schreb) e também em solo sem cobertura. Amostras de solo e palha foram coletadas imediatamente após a aplicação do imazaquin. Vinte e quatro horas após a aplicação do herbicida, o experimento foi irrigado e novas amostras foram coletadas para bioensaios e análises cromatográficas. A população de ervas era formada por Brachiaria plantaginea, Euphorbia heterophylla e Bidens pilosa. Antes da irrigação, os resíduos de aveia interceptaram aproximadamente $90 \%$ do produto em 7000 e $14000 \mathrm{~kg} / \mathrm{ha}$ de cobertura. Praticamente todo o imazaquin foi lixiviado para o solo após a irrigação. Esses resultados indicam que $o$ imazaquin tem perspectivas de uso em plantio direto na palha.

Palavras chave: Herbicidas, cromatografia, resíduos vegetais.

\begin{abstract}
\section{Mulch influence on weed-crop competition and on imazaquin retention in no tillage soybean crop}

The plant residues are the main part of the no-tillage system. Although the coverage reduces weed population density, they might intercept herbicides when applied on the mulch. Field experiments, bioassays and chromatographic analysis were made using imazaquin at the rates: zero, 75, 150 and $300 \mathrm{~g} / \mathrm{ha}$ applied on 7000 and $14000 \mathrm{~kg} / \mathrm{ha}$ of oat residues and on soil without mulch. Soil and straw samples were collected

was irrigated and more samples were collected for bioassays and chromatographics analysis. The weed population were formed by Brachiaria plantaginea, Euphorbia heterophylla and Bidens pilosa. Before irrigation, the oat residues intercepted approximately $90 \%$ from 7000 to $14000 \mathrm{~kg} / \mathrm{ha}$. Imazaquin has a great chance to be used in no-till system.
\end{abstract} immediately after imazaquin application. Twenty four hours after imazaquin application the field
Key words: Herbicides, chromatography, residues.

\footnotetext{
${ }^{1}$ Recebido para publicação em 20/08/99 e na forma revisada em 04/10/99.

${ }^{2} \mathrm{Eng}^{\mathrm{O}} \mathrm{Agr}^{\mathrm{O}} \mathrm{PhD}$, Pesquisador do IAPAR, C.P. 481, CEP: 86001-970, Londrina/PR.

${ }^{3}$ Eng $^{\mathrm{o}}$ Químico MSc, Pesquisador do IAPAR, C.P. 481, CEP: 86001-970, Londrina/PR.

${ }^{4}$ Eng $^{\mathrm{a}}$ Agr $^{\mathrm{a}}$ MSc, Pesquisadora do IAPAR, C.P. 481, CEP: 86001-970, Londrina/PR.

${ }^{5}$ Alunos do curso de Mestrado da UEL, C.P. 6001, CEP: 86051-970, Londrina/PR.
} 


\section{INTRODUÇÃO}

O sistema de plantio direto ocupa hoje grandes áreas em todo o Brasil, constituindo-se num dos mais importantes sistemas agrícolas de conservação de solo que se conhece.

$\mathrm{Na}$ cultura da soja, semeada no sistema de plantio direto sobre cobertura morta de aveia-preta (Avena strigosa), há possibilidade de se reduzir ou até mesmo dispensar o uso de herbicidas (Almeida \& Rodrigues, 1985; Almeida, 1988). No entanto, no campo, com frequência aumentamse as doses dos herbicidas residuais em plantio direto, onerando-se o custo de produção. Essas práticas ocorrem em parte porque os mesmos herbicidas recomendados para plantio convencional, são também recomendados sem modificação nas dosagens (Rodrigues \& Almeida, 1998) para o plantio direto. Às vezes, aumenta-se também a pressão e a vazão do pulverizador, visando inutilmente facilitar a penetração do produto na camada de palha (Fornarolli, 1997).

Sabe-se que a cobertura morta oriunda da aveia-preta pode interceptar até $85 \%$ do atrazine (Fornarolli, 1997). No entanto, uma chuva de $20 \mathrm{~mm}$ ocorrendo 24 horas após a aplicação, lixivia praticamente todo o produto da palha para o solo. Banks \& Robinson (1982), verificaram que menos de $1 \%$ do metribuzin alcançou o solo coberto de palha antes da irrigação e que 56\% desse produto atingiu o solo depois da irrigação.

$\mathrm{O}$ teor de alachlor, acetochlor e metolachlor em solo com $4480 \mathrm{~kg} / \mathrm{ha}$ de cobertura morta, é menor que em solo com $2240 \mathrm{~kg} / \mathrm{ha}$ de cobertura, evidenciando a retenção desses herbicidas na palha (Banks \& Robinson, 1986). O clomazone parece ser fortemente adsorvido à palha, mesmo ocorrendo $20 \mathrm{~mm}$ de chuvas imediatamente após a aplicação (Rodrigues, 1993).

Dentro dessa linha de pesquisa, delineouse o presente trabalho, cujo objetivo é estudar o comportamento do herbicida imazaquin quando aplicado em diferentes doses sobre diferentes quantidades de cobertura morta de aveia-preta, no sistema de plantio direto.

\section{MATERIAL E MÉTODOS}

O trabalho foi realizado na safra $1997 / 98$ em condições de campo e em "telado". O clima do local é Cfa da escala de Koeppen. O solo é do tipo Latossolo Roxo distrófico, com horizonte A moderado, de textura argilosa ( $81 \%$ de argila, $8 \%$ de silte e $11 \%$ de areia), fase tropical perenifolia e relevo suave ondulado. Foram realizados dois experimentos a campo e um bioensaio.

No experimento $\mathrm{n}^{\circ} 01$ a campo, foi adotado o esquema de blocos ao acaso, com parcelas subdivididas, com quatro repetições. As parcelas foram constituídas de cobertura morta oriunda de palha de aveia-preta em níveis de zero; 7,0 e 14,0 t/ha de matéria seca, distribuída no momento da instalação do experimento. As subparcelas $(3 \times 6 \mathrm{~m})$ foram constituídas pelas doses de imazaquin: zero, 75, 150 e $300 \mathrm{~g} / \mathrm{ha}$. Em cada subparcela a área útil foi de $2 \times 5 \mathrm{~m}$. Lateralmente a cada subparcela, foram deixadas faixas com $1 \mathrm{~m}$ de largura, não tratadas, que foram utilizadas como termo de comparação nas avaliações visuais.

Usou-se glyphosate $(0,54 \mathrm{~kg} / \mathrm{ha}$ i.a.) como dessecante da aveia-preta. A seguir foi feita a "rolagem" (passada de "rolo-faca"). $\mathrm{Na}$ testemunha, sem cobertura, a aveia-preta foi retirada manualmente das parcelas. Utilizando a palha já dessecada ajustou-se a quantidade de palha nos outros tratamentos (7 e $14 \mathrm{t} / \mathrm{ha})$. A seguir foi semeada a soja no sistema de plantio direto, ao espaçamento de $0,5 \mathrm{~m}$ entre linhas. A adubação utilizada foi de $300 \mathrm{~kg} / \mathrm{ha}$ da formulação 04-30-10.

Após a semeadura, aplicou-se imazaquin em pré-emergência, utilizando pulverizador de pressão constante $\left(\mathrm{CO}_{2}\right)$, munido com barra de seis bicos "Teejet Flat Spray" 80.02, distanciados $50 \mathrm{~cm}$ entre si e vazão de 200 1/ha. Um dia após a aplicação, o experimento foi irrigado por aspersão, aplicando-se $20 \mathrm{~mm}$ de água, para favorecer a lixiviação do herbicida da palha para o solo.

Tanto após a aplicação do imazaquin como após a irrigação, foram coletadas amostras de solo nas subparcelas, na profundidade de 0 a 
$10 \mathrm{~cm}$ utilizando um aro com $20 \mathrm{~cm}$ de diâmetro por $10 \mathrm{~cm}$ de altura. As amostras foram colocadas em vasos plásticos e levadas para os bioensaios em "telado", para se detectar a presença do imazaquin no solo utilizando-se pepino como planta-teste. Nos bioensaios foram feitas avaliações de fitotoxicidade, através da medição de altura das plantas aos 30 dias depois da semeadura, quando então os bioensaios foram encerrados.

No experimento $\mathrm{n}^{\circ} 01$ de campo, foram feitas as seguintes avaliações: a) visual de fitotoxicidade na cultura da soja e de controle de plantas daninhas (escala $0-100 \%$ ) aos 25 dias após a aplicação (DAA), onde $0=$ nenhum sintoma e $100=$ morte total da planta; b) contagem do número de plantas daninhas (por espécie) presentes por metro quadrado aos $25 \mathrm{DAA}$; c) matéria seca das plantas daninhas antes da colheita $\left(\mathrm{g} / \mathrm{m}^{2}\right)$; d) produção de grãos da cultura $(\mathrm{kg} / \mathrm{ha})$. Nesse experimento, havia três espécies de plantas daninhas presentes: capim-marmelada (Brachiaria plantaginea); amendoim-bravo (Euphorbia heterophylla) e picão-preto (Bidens pilosa).

Foi realizado também, em condições de campo, um segundo experimento (experimento $\mathrm{n}^{\circ}$ 02) também em blocos ao acaso, com parcelas subdivididas. As parcelas principais foram constituídas pelas seguintes quantidades de palha: 7,0 e 14,0 t/ha de matéria seca de palha de aveiapreta; as subparcelas foram constituídas pelas seguintes quantidades de chuva, aplicadas 24 horas após a aplicação do imazaquin: zero, 20, 40, 60,80 e $100 \mathrm{~mm}$. A dose única de imazaquin utilizada, neste caso, foi de $150 \mathrm{~g} / \mathrm{ha} \quad(1,0 \mathrm{l} / \mathrm{ha}$ de Scepter $150 \mathrm{~g} / \mathrm{l})$. Neste experimento, foram retiradas amostras de palha antes e após cada irrigação, para análise cromatográfica de resíduos do herbicida. Utilizou-se como amostrador um aro de $20 \mathrm{~cm}$ de diâmetro.

As quantificações analíticas dos resíduos de imazaquin na palha, foram feitas através das técnicas de cromatografia de fase líquida (HPLC), baseando-se na metodologia desenvolvida pela American Cyanamid Company (1988). O resíduo de imazaquin foi extraido das amostras com solução aquosa de hidróxido de sódio $0,5 \mathrm{~N}$ durante um período de duas horas sob agitação constante. O "cleanup" foi realizado através do sistema de colunas de extração de fase sólida C18 e SCX seguido de partição com diclorometano. Os extratos purificados foram concentrados em rotavapor e quantificados por cromatografia de fase líquida com comprimento de onda de $240 \mathrm{~nm}$.

Todos os resultados foram submetidos a análise de regressão.

\section{RESULTADOS E DISCUSSÃO}

A fitotoxicidade do imazaquin aos 25 dias após a aplicação (DAA), foi caracterizada principalmente por redução na altura da soja, sendo que os efeitos mais severos foram observados com a dose dupla, nas tres quantidades de palha estudadas (Figura 1).

As porcentagens de controle e o número de plantas $/ \mathrm{m}^{2}$ aos 25 DAA das espécies presentes no campo encontram-se na Figura 2. No caso da $B$. plantaginea, nota-se que, mesmo na dose dupla em solo descoberto, o controle (A) foi praticamente igual ao proporcionado por $7 \mathrm{t} / \mathrm{ha}$ de palha sem a aplicação do produto $(69 \%$ contra $71 \%$ ). O número de plantas de B. plantaginea (D) em solo sem cobertura e sem herbicida, era de 238 plantas $/ \mathrm{m}^{2}$. Esse número caiu para 50 plantas $/ \mathrm{m}^{2}$ nas parcelas com $7 \mathrm{t} / \mathrm{ha}$ de palha e 5 plantas $/ \mathrm{m}^{2}$ nas parcelas com $14 \mathrm{t} / \mathrm{ha}$. Em relação à E. heterophylla, observa-se que a dose mínima necessária para se obter um controle satisfatório dessa espécie em solo sem cobertura foi de $150 \mathrm{~g} / \mathrm{ha}$ (B). Essa porcentagem de controle, no entanto, foi obtida com a dose zero nas parcelas com 7 t/ha de palha. $\mathrm{O}$ número de plantas de E. heterophylla (E) que era de 29 plantas $/ \mathrm{m}^{2}$ nas parcelas sem cobertura e sem herbicida, caiu para 19 plantas $/ \mathrm{m}^{2}$ com $7 \mathrm{t} / \mathrm{ha}$ de palha e para 6 plantas $/ \mathrm{m}^{2}$ com $14 \mathrm{t} / \mathrm{ha}$ de palha. 


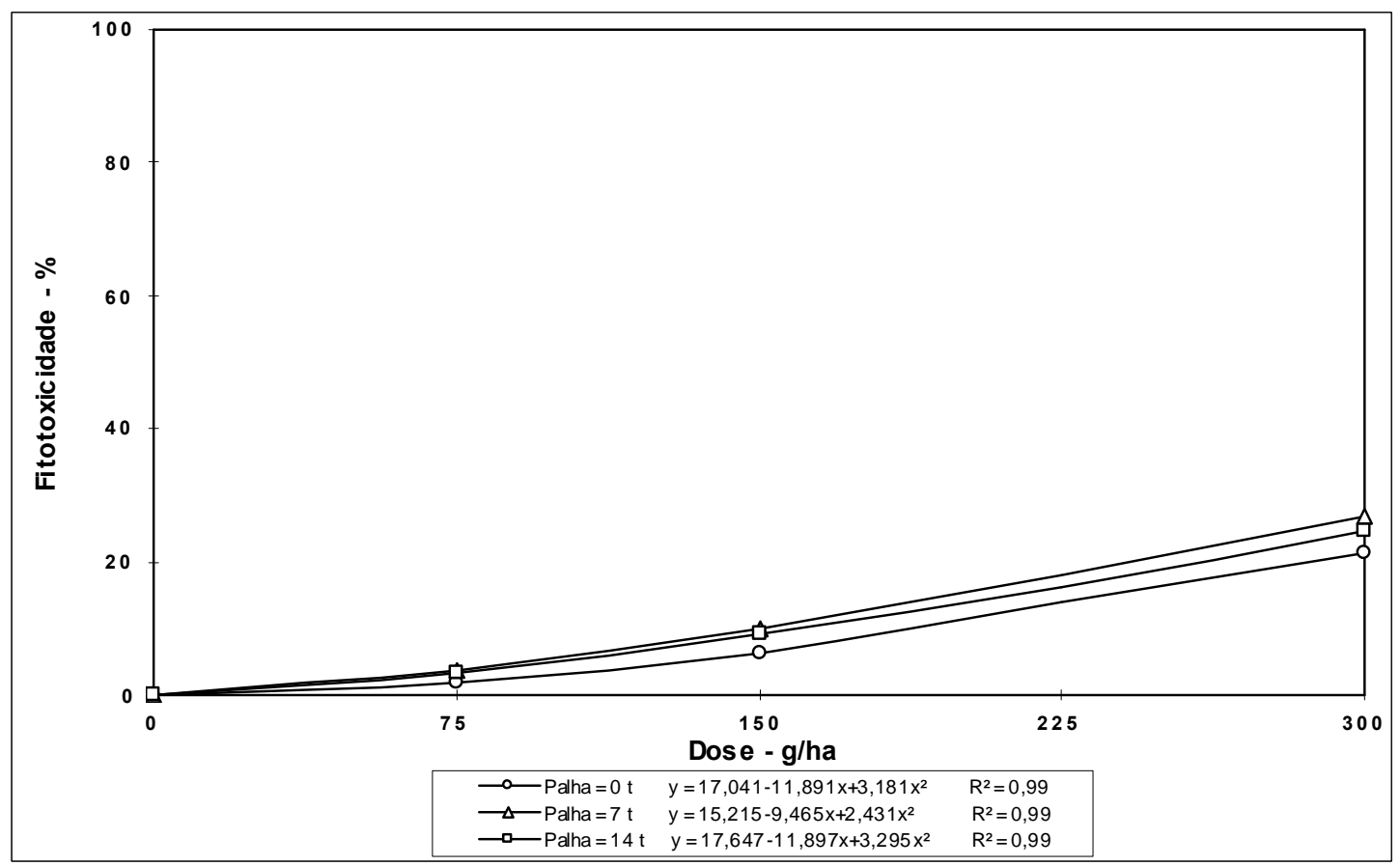

FIGURA 1. Influência da quantidade de palha e da dose de imazaquin na fitotoxicidade do produto na soja aos 25 dias após a aplicação.

No caso do B. pilosa, verifica-se que foi necessário $150 \mathrm{~g} / \mathrm{ha}$ de imazaquin nas parcelas sem cobertura morta, para proporcionar um controle relativamente satisfatório e semelhante ao proporcionado por $75 \mathrm{~g} / \mathrm{ha}$ desse herbicida nas parcelas com 7 t/ha de palha (C). O número de plantas de B. pilosa $(\mathrm{F})$ que era de 35 plantas $/ \mathrm{m}^{2}$ nas parcelas sem cobertura e sem herbicida, caiu para 20 plantas $/ \mathrm{m}^{2}$ com 7 t/ha de palha e para 2 plantas $/ \mathrm{m}^{2}$ com $14 \mathrm{t} / \mathrm{ha}$ de palha . Esses valores refletiram na biomassa seca das infestantes (Figura 3) e na produção de grãos da cultura (Figura 4). Verifica-se que, com a redução da matocompetição, a produtividade da cultura foi maior. Resultados semelhantes foram obtidos por Fornarolli (1997), utilizando o herbicida atrazine na cultura do milho e também por Rodrigues et al. (1998) , com trifluralin. Os resultados mostram que, com o aumento da dose de imazaquin, de zero para $150 \mathrm{~g} / \mathrm{ha}$, houve um consequente aumento na produção da soja, em solo descoberto e também com 7,0 t/ha de cobertura morta. No entanto, nas parcelas com $14 \mathrm{t} / \mathrm{ha}$ de palha, as doses não influíram na produção da soja.

Nos bioensaios realizados em "telado" (Figura 5), observou-se que o desenvolvimento do pepino foi drasticamente afetado quando este foi semeado em solo retirado das parcelas sem cobertura morta e antes da irrigação (A). A redução de altura foi de aproximadamente $50 \%$ entre a dose zero e a dose $150 \mathrm{~g} / \mathrm{ha}$, mantendo-se com esse percentual na dose $300 \mathrm{~g} / \mathrm{ha}$. No entanto, quando semeado em solo retirado sob a cobertura, a altura praticamente não sofreu alteração, mantendo-se ao redor de $15 \mathrm{~cm}$, independente da quantidade de palha ou da dose do produto aplicada. Isso demonstra que o produto ficou retido na palha, não atingindo o solo. 
Influência da cobertura morta na retenção do imazaquin em plantio direto de soja
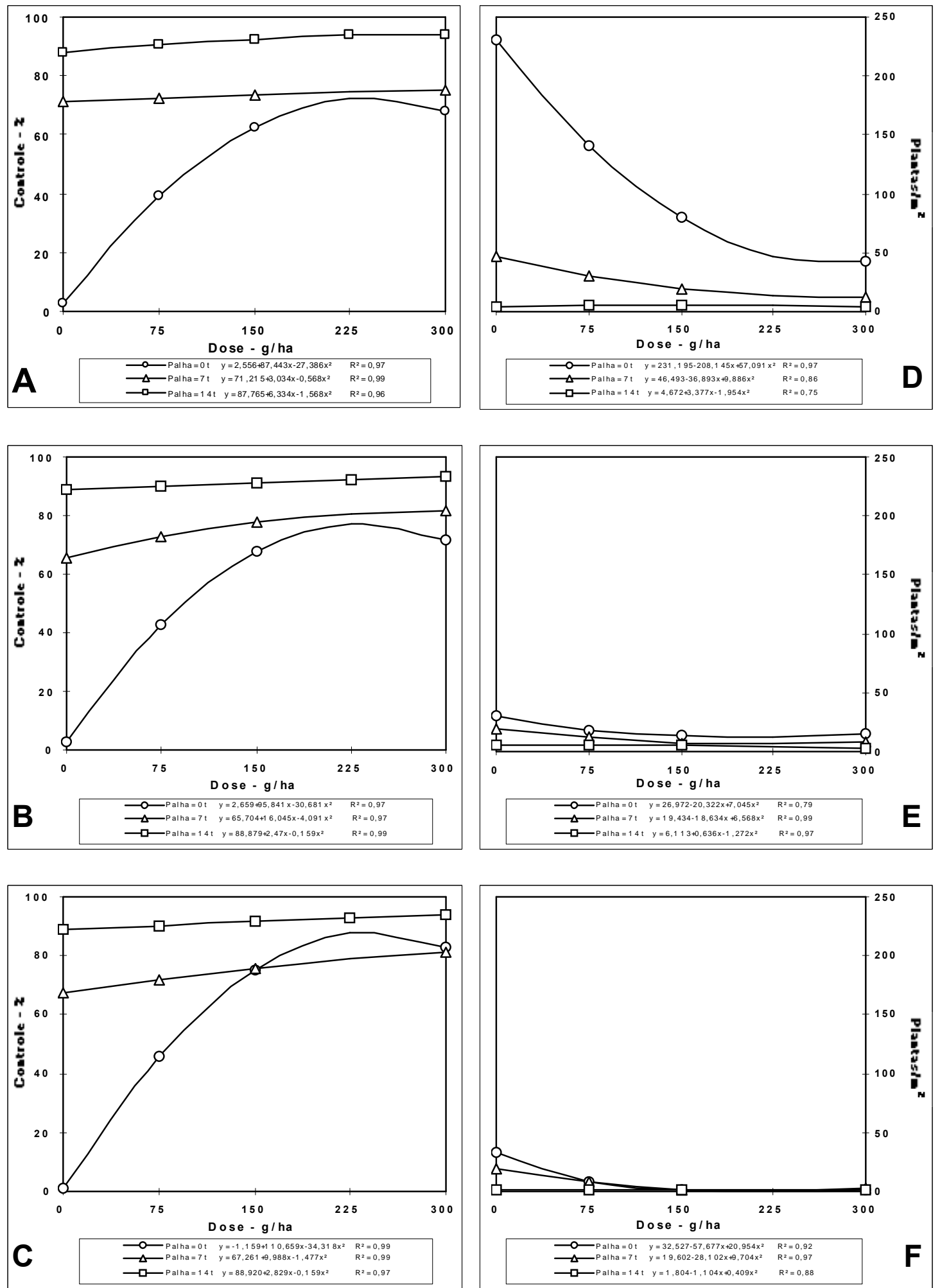

FIGURA 2. Influência da quantidade de palha e da dose de imazaquin na porcentagem de controle e no número de plantas $/ \mathrm{m}^{2}$ de B. plantaginea (A e D), E. heterophylla (B e E) e B. pilosa $(\mathrm{C}$ e F). 


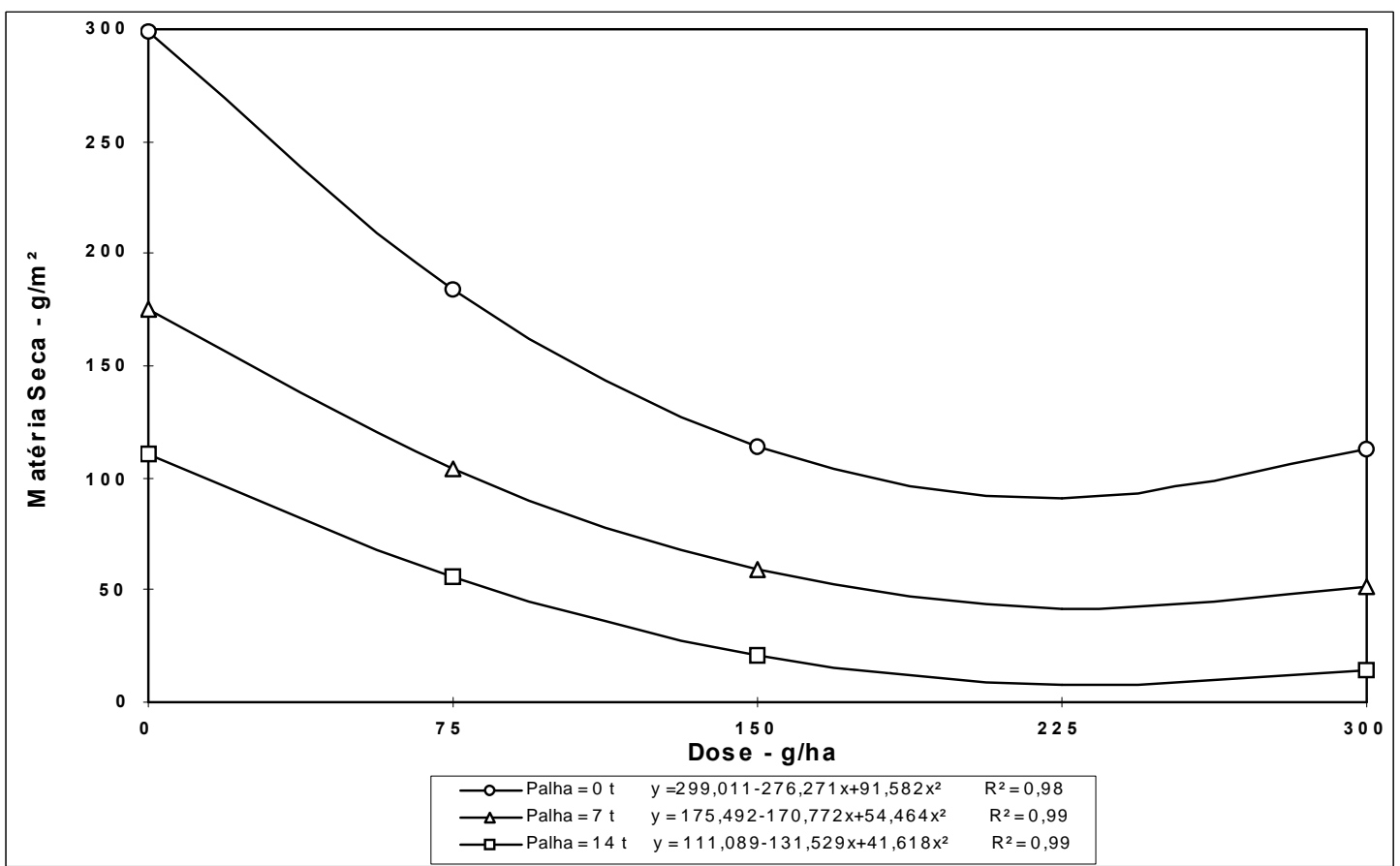

FIGURA 3. Influência da quantidade de palha e da dose de imazaquin no peso da matéria seca das plantas daninhas na época da colheita da soja.

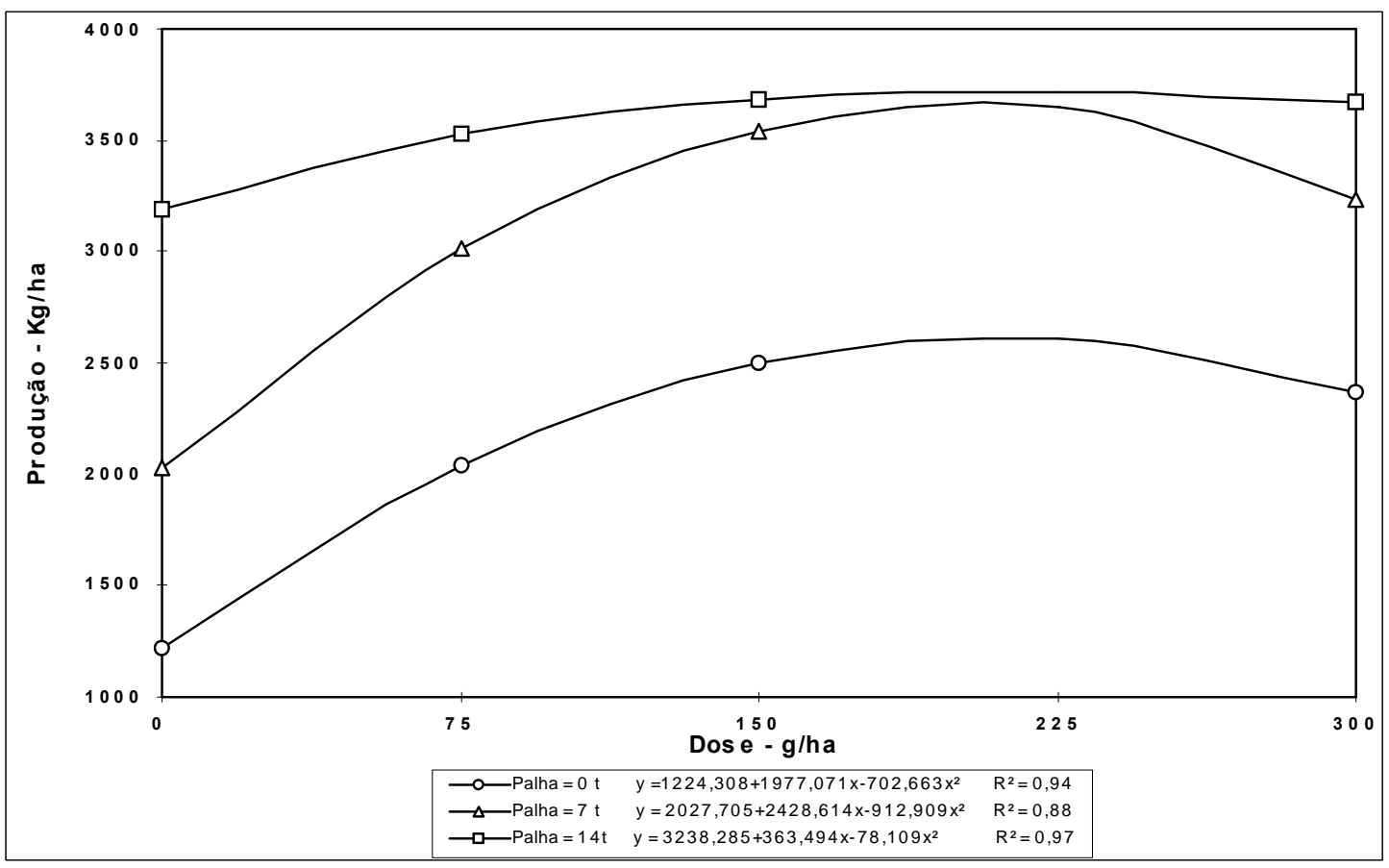

FIGURA 4. Influência da quantidade de palha e da dose de imazaquin na produção da soja. 
Influência da cobertura morta na retenção do imazaquin em plantio direto de soja
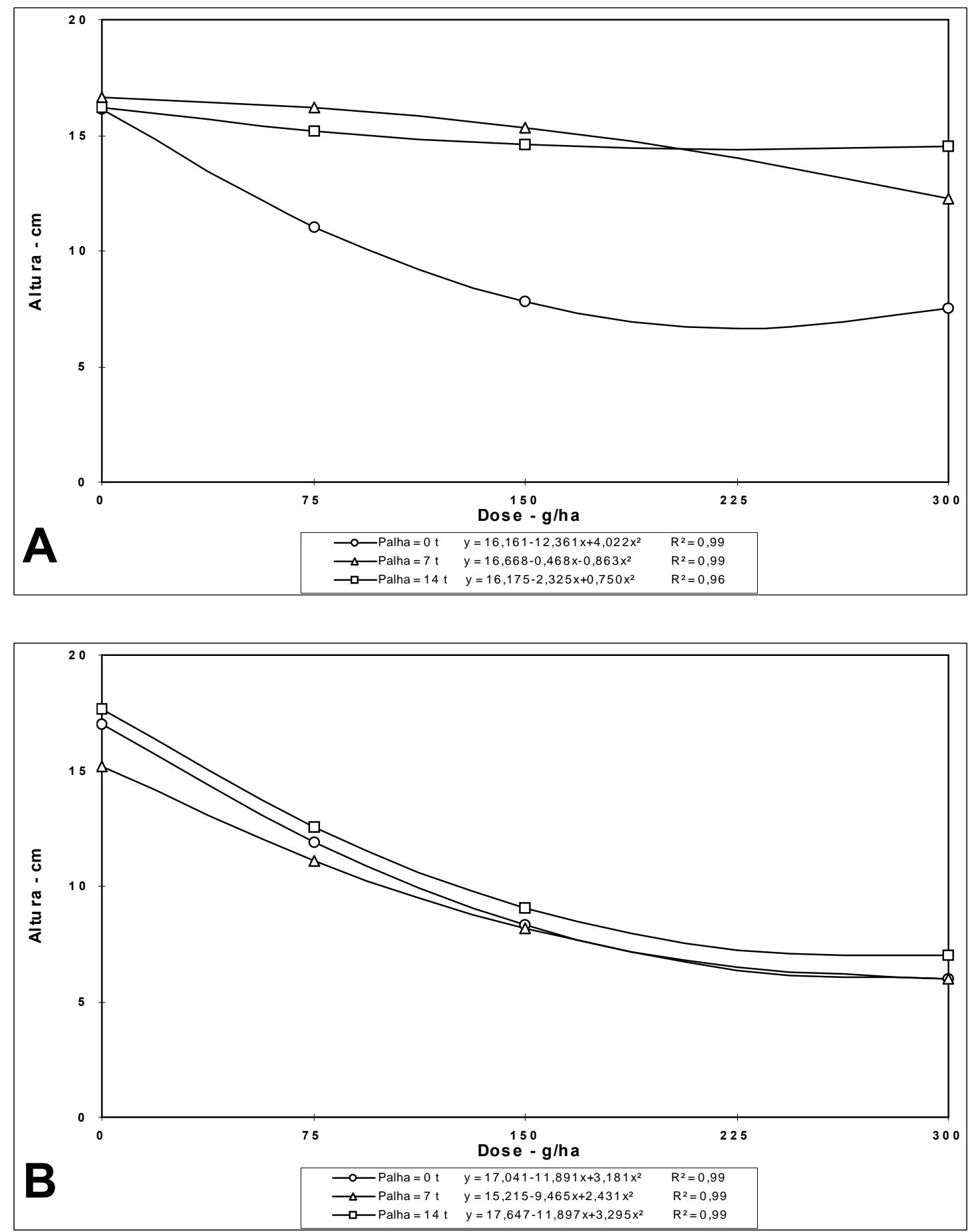

FIGURA 5. Influência da quantidade de palha e da dose de imazaquin na altura do pepino aos 30 dias após a semeadura deste, em bioensaio com solo retirado antes (A) e depois (B) da irrigação. 
Por outro lado, as plantas de pepino obtidas em solos retirados das parcelas após a irrigação (B), apresentaram sintomas drásticos de fitotoxicidade, notadamente redução de altura. Não houve praticamente diferenças entre as plantas dentro de uma mesma dose. A redução de altura foi de aproximadamente $50 \%$ entre a dose zero e a dose $300 \mathrm{~g} / \mathrm{ha}$, em todas as quantidades de palha estudadas. Isso demonstra que, com a irrigação, o produto foi lixiviado da palha para o solo. Esses resultados confirmam os observados por Rodrigues (1993) com o próprio imazaquin, em ensaios preliminares. Comportamento semelhante foi observado por Fornarolli (1997) com atrazine.

Mais de $90 \%$ do imazaquin aplicado ficou retido na palha antes da irrigação, confirmando os dados do bioensaio (Figura 6). Após a irrigação, no entanto, menos de $7 \%$ em média ficou na palha, sendo que $20 \mathrm{~mm}$ de chuva foram suficientes para promover a lixiviação do produto da palha para o solo. Esses resultados foram também observados por Rodrigues (1993) com esse mesmo herbicida, ocasião em que a primeira chuva ocorreu apenas uma semana após a aplicação do imazaquin. De forma semelhante, Fornarolli (1997), verificou que $85 \%$ do atrazine fica retido na palha, e que uma chuva de $20 \mathrm{~mm}$ é suficiente para levar praticamente todo o produto da palha para o solo. Concluindo, podemos dizer que: 1) Aproximadamente 90\% do imazaquin fica retido na palha antes da irrigação; no entanto, $20 \mathrm{~mm}$ de chuva são suficientes para promover a lixiviação desse herbicida para o solo. 2) $\mathrm{O}$ imazaquin tem boas perspectivas de uso em préemergência, no sistema de plantio direto na palha.

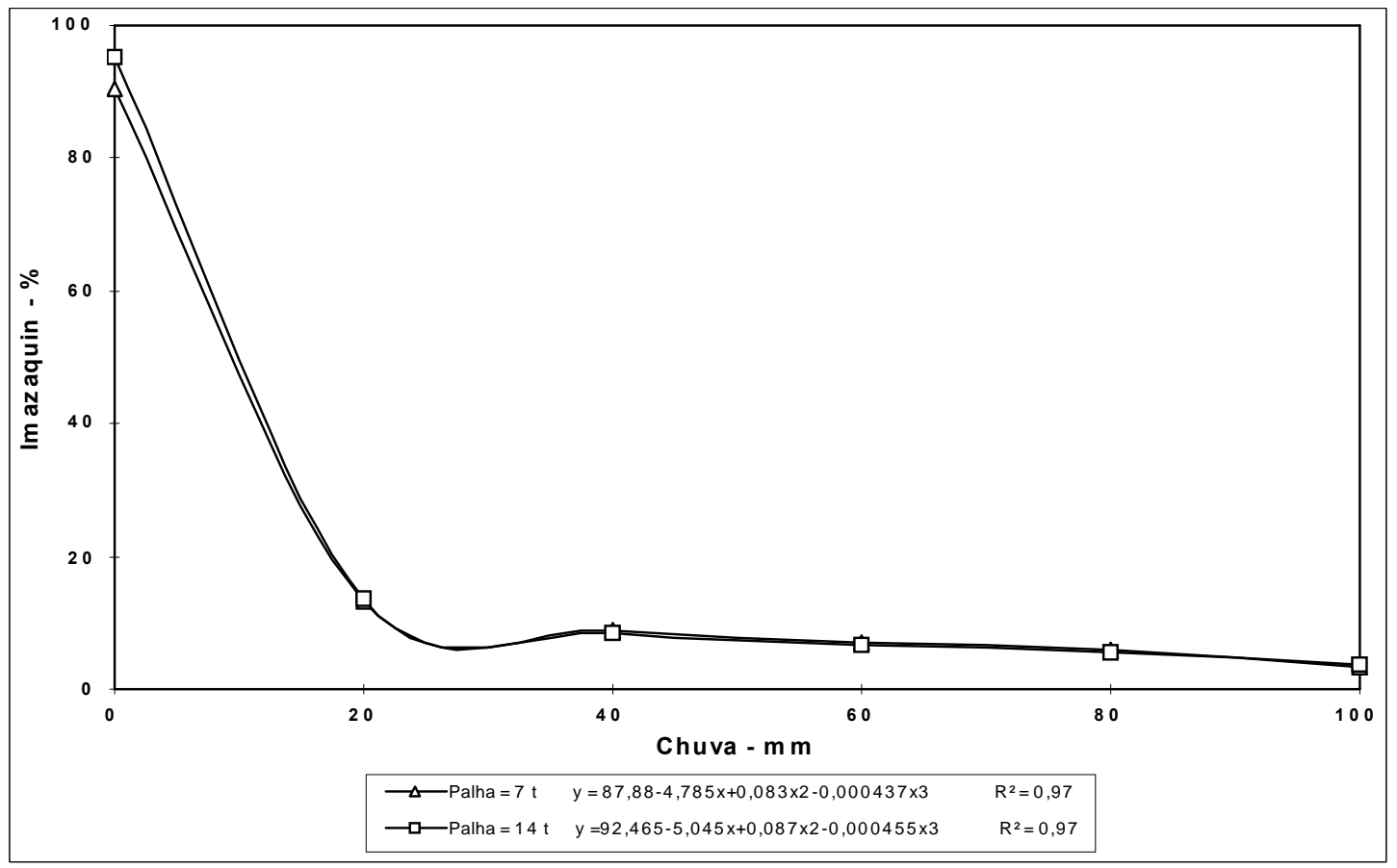

FIGURA 6. Influência da quantidade de palha e de chuva na porcentagem de imazaquin retido na palha, em plantio direto de soja. 


\section{LITERATURA CITADA}

ALMEIDA, F.S. A alelopatia e as plantas. Londrina, IAPAR, 1988. 60 p. (Circular IAPAR, 53).

ALMEIDA, F.S. \& RODRIGUES, B. N. Guia de Herbicidas. Contribuição para o uso adequado em plantio direto e convencional. Londrina, IAPAR/GTZ. 1985. 450p.

\section{AMERICAN CYANAMID COMPANY AGRICULTURAL \\ DIVISION, RESEARCH \\ DEVELOPMENT. P. O. Box 400, Princeton, New Jersey 08540 USA, 1988.}

BANKS, P.A. \& ROBINSON, E.L. Soil reception and activity of acetochlor, alachlor and metolachlor as affected by wheat (Triticum aestivum) straw and irrigation. Weed Sci., v.34, n.4, p.607-611. 1986.
BANKS, P.A. \& ROBINSON, E.L. The influence of straw mulch on the soil reception and persistence of metribuzin. Weed Sci., v.30, n.2, p.164-8. 1982.

FORNAROLLI, D.A. Influência da cobertura morta no comportamento do herbicida atrazine. UEL-Londrina, PR. 1997. Dissertação de Mestrado.

RODRIGUES, B.N. Influência da cobertura morta no comportamento dos herbicidas imazaquin e clomazone. Planta Daninha, v.11, n.1 e 2, p.21-8, 1993.

RODRIGUES, B.N. \& ALMEIDA, F.S. Guia de Herbicidas. 3.ed. Londrina, PR, Ed. dos autores, 1998. 648p.

RODRIGUES, B.N.; LIMA, J.; YADA, I.F.U.; FORNAROLLI, D.A. Influência da cobertura morta no comportamento do herbicida trifluralin. Planta Daninha, v.16, n.2., p.163-173. 1998. 